\title{
Formulation and Make-Up of Simulated Acidic Concentrated Water (SAW), High Ionic Content Aqueous Solution
}

\author{
Greg Gdowski
}

September 30, 1996

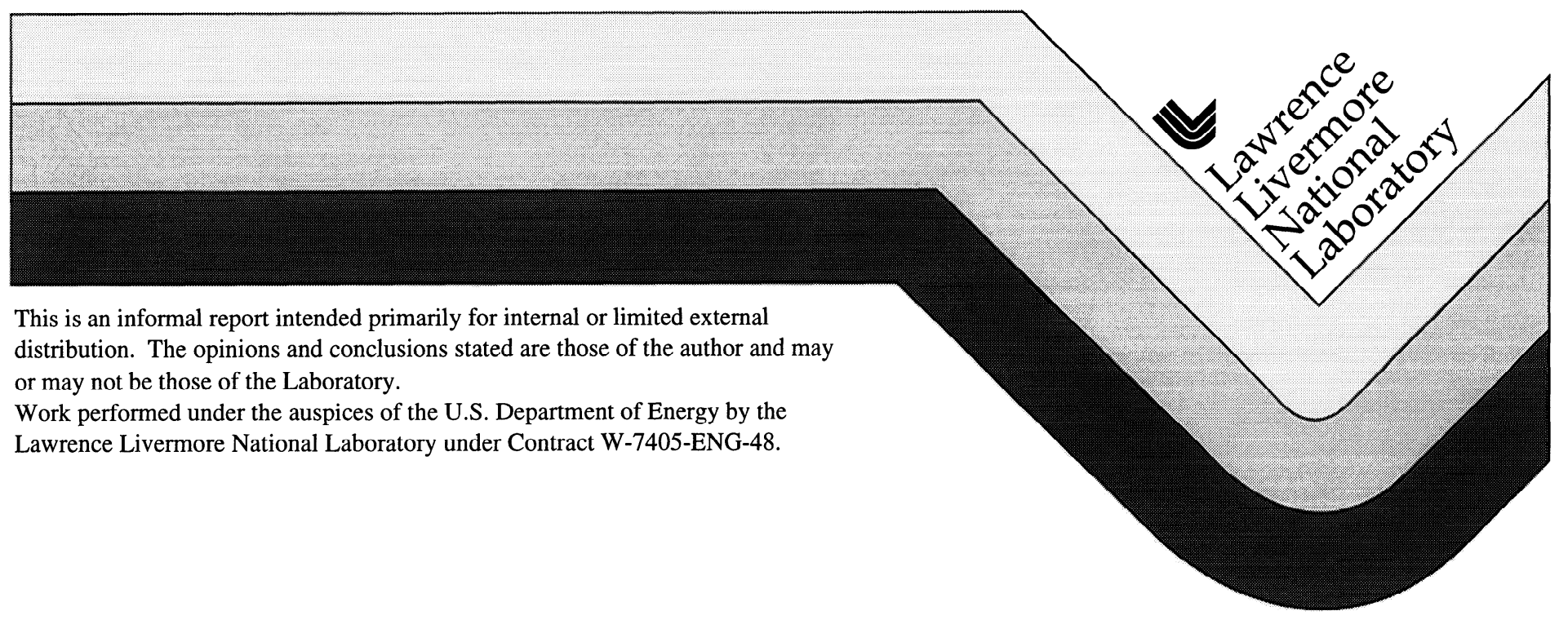




\section{DISCLAIMER}

This document was prepared as an account of work sponsored by an agency of the United States Government. Neither the United States Government nor the University of California nor any of their employees, makes any warranty, express or implied, or assumes any legal liability or responsibility for the accuracy, completeness, or usefulness of any information, apparatus, product, or process disclosed, or represents that its use would not infringe privately owned rights. Reference herein to any specific commercial product, process, or service by trade name, trademark, manufacturer, or otherwise, does not necessarily constitute or imply its endorsement, recommendation, or favoring by the United States Government or the University of California. The views and opinions of authors expressed herein do not necessarily state or reflect those of the United States Government or the University of California, and shall not be used for advertising or product endorsement purposes.

This report has been reproduced directly from the best available copy.

Available to DOE and DOE contractors from the

Office of Scientific and Technical Information P.O. Box 62, Oak Ridge, TN 37831

Prices available from (423) 576-8401

Available to the public from the National Technical Information Service

U.S. Department of Commerce 5285 Port Royal Rd., Springfield, VA 22161 


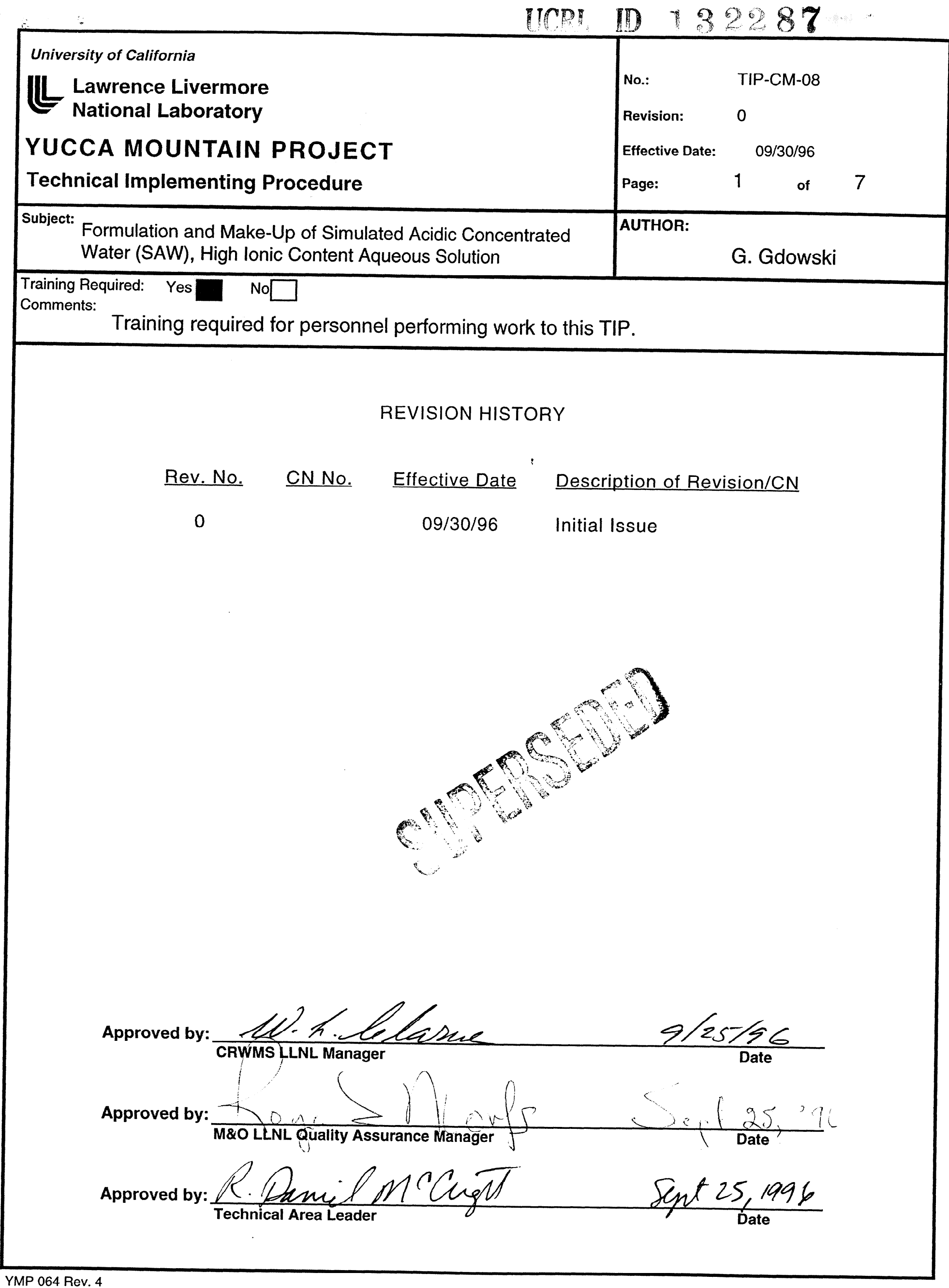




\begin{tabular}{|l|l|l|l|ll|}
\hline No.: & Revision: & Date: & Page: & \\
& 0 & $09 / 30 / 96$ & of & 7 \\
\hline
\end{tabular}

\subsection{PURPOSE}

This procedure describes the formulation and make-up of Simulated Acidified Water (SAW), a high-ioniccontent water to be used for Activity E-20-50 "Long-Term Corrosion Studies." Acidic solutions at the repository may result as a consequence of microbial activity. In formulating the ionic composition of the SAW, it was attempted to simulate the acidification of high ionic content water contacting a waste package. Therefore, the composition of this water is based on the acidification of the Simulated Concentrated Water (SCW), which is described in TIP-CM-07. The pH of the solution will be controlled at a nominal value of 2 .

Acidification of SCW would result in the removal of bicarbonate from solution by formation of gaseous $\mathrm{CO}_{2}$; in acidic solution $\mathrm{HCO}_{3}$ - is converted to $\mathrm{H}_{2} \mathrm{CO}_{3}$ and finally to $\mathrm{CO}_{2}$ and $\mathrm{H}_{2} \mathrm{O}$. Hydrogen flouride (HF) is also volatile under acidic conditions and will also be removed from solution. The ionic content of the SAW solution was set by replacing on a molar basis the bicarbonate and flouride ions with sulfate, chloride, and nitrate. The concentration increases were ratioed according to the concentrations already in solution. Also $1,000 \mathrm{ppm}$ of $\mathrm{Ca}^{2+}$ and $\mathrm{Mg}^{2+}$ were included to account for the solubility of carbonates in acidic solutions. Calcium and magnesium solubility is limited in high bicarbonate waters.

(For reference the SCW solution has an ionic content which is nominally a factor of a thousand higher than that of "representative" waters at or near Yucca Mountain. "Representative" waters were chosen as J-13 well water [Harrar, 1990] and "perched" water at Yucca Mountain [Glassley, 1996] (see Table 1 in TIP-CM-07). J-13 well water is obtained from ground water that is in contact with the Topopah Spring tuff, which is the repository horizon rock. The "perched" water is located in the Topopah Spring tuff, but below the repository horizon and above the water table. A nominal thousand times higher ionic content was chosen to simulate the water that would result from the wetting of salts which have been previously deposited on a container surface.)

The theorectical composition of the SAW is given in Table 1; the SCW theoretical composition is included for reference. It is expected that the actual composition of test solutions will be within $\pm 20 \%$ of these values. The changes in the corrosive properties of the test solutions will be acceptable within these values. In addition similar type materials are tested in the same test vessel, so vessel to vessel variation of solution composition is of limited significance.

This aqueous solution is one of the four aqueous test solutions to be used in the activity. The other aqueous solutions included a simulated dilute water (SDW), a simulated concentrated water (SCW), and a simulated basic concentrated water (SBW).

This TIP documents the chemical reagents, reactant air, and the procedures used to make-up the aqueous solution for Activity E-20-50. More than 9,000 liters (2,400 gallons) of simulated acidic concentrated water solution are required for the test vessels for implementation of the full test matrix of the activity plan.

\subsection{SCOPE}

This procedure applies to the simulated acidic concentrated water solution, one of the aqueous solutions that are to be used in the test vessels for Activity E-20-50 "Long-Term Corrosion Studies."

\subsection{RESPONSIBILITIES}

The Principal Investigator $(\mathrm{PI})$ or designee is responsible for:

- $\quad$ the conduct of the activities and methods described in this procedure, and

- $\quad$ maintaining laboratory scientific notebooks. 
The Task Area Leader (TAL) is responsible for:

- $\quad$ ensuring that the requirements of this procedure are implemented,

- $\quad$ ensuring that personnel conducting the work are qualified and are trained to this procedure,

- $\quad$ verifying that this procedure meets the objectives of the Scientific Investigation Plan (SIP) "Metal Barrier Selection and Testing" (SIP-CM-01, Rev.3, WBS \# 1.2.2.5.1) and Activity E-20-50 "LongTerm Corrosion Studies", and

- $\quad$ ensuring approval of this procedure.

The YMP Quality Assurance Manager (QA Manager) is responsible for:

- $\quad$ monitoring the work to assure proper implementation of this procedure, and

- $\quad$ assuring its continued effectiveness.

\section{0}

\section{COMPOSITION OF SCW AND REACTANT AIR}

\subsection{Aqueous Solution Composition}

The simulated acidic concentrated water (SAW) solution has a ionic composition that is expected to result from acidification of the SCW solution. Fluoride and bicarbonate ions are not expected to remain in solution because of the expected volatilization of $\mathrm{HF}$ and $\mathrm{CO}_{2} ; \mathrm{CO}_{2}$ formed by the decomposition of $\mathrm{H}_{2} \mathrm{CO}_{3}$. To maintain the high ionic concentration of the solution, sulfate, chloride, and nitrate ions are added to replace on a molar basis the loss of bicarbonate and flouride. The increases were made proportional to the solution concentration ratios. Magnesium and calcium concentration were arbitrarily increased to $1000 \mathrm{ppm}$ to simulate the possiblity of dissolution of $\mathrm{MgCO}_{3}$ and $\mathrm{CaCO}_{3}$ in acidic solutions. As with the other solutions, silica content is based on solubility of $\alpha$-cristobalite which is believed to be the dominant soluble silica phase of Yucca Mountain rock at 60 and $90^{\circ} \mathrm{C}$ [Wolery, 1983; Knauss, 1987]. Silica will be added to the solution by dissolution of sodium silicate.

The estimated composition of the SCW is given in Table 1. It is expected that the actual composition of test solutions will be within $\pm 20 \%$ of these values. The changes in the corrosive properties of the test solutions within these values will not be significant. In addition similar type materials are tested in the same test vessel, so vessel-to-vessel variation of solution composition is of limited significance.

Table 1. The theorectical nominal compositions of the simulated acidic concentrated water and the simulated concentrated water.

\begin{tabular}{lll}
\hline Constituent & $\begin{array}{l}\text { Simulated concentrated } \\
\text { acidic water (estimated) } \\
(\mathrm{mg} / \mathrm{l})\end{array}$ & $\begin{array}{l}\text { Simulated concentrated } \\
\text { water (estimated) } \\
(\mathrm{mg} / \mathrm{l})\end{array}$ \\
\hline $\mathrm{Na}$ & 37,690 & 40,900 \\
$\mathrm{Si}$ & $27(60 \mathrm{C}) ; 49(90 \mathrm{C})$ & $27(60 \mathrm{C}) ; 49(90 \mathrm{C})$ \\
$\mathrm{Ca}$ & 1,000 & $<1$ \\
$\mathrm{~K}$ & 3,400 & 3,400 \\
$\mathrm{Mg}$ & 1,000 & $<1$ \\
$\mathrm{~F}^{-}$ & 0 & \\
$\mathrm{Cl}^{-}$ & 24,250 & 1,400 \\
$\mathrm{NO}_{3}^{-}$ & 23,000 & 6,700 \\
$\mathrm{SO}_{4}{ }^{-}$ & 38,600 & 6,400 \\
$\mathrm{HCO}_{3}^{-}$ & 0 & 16,700 \\
& & 70,000
\end{tabular}




\begin{tabular}{|l|l|l|l|l|l|}
\hline No: & Revision: & Date: & Page: & \\
& 0 & $09 / 30 / 96$ & 4 & 7 \\
\hline
\end{tabular}

\begin{tabular}{lll}
\hline Constituent & $\begin{array}{l}\text { Simulated concentrated } \\
\text { acidic water (estimated) } \\
(\mathrm{mg} / \mathrm{l})\end{array}$ & $\begin{array}{l}\text { Simulated concentrated } \\
\text { water (estimated) } \\
(\mathrm{mg} / \mathrm{l})\end{array}$ \\
\hline $\mathrm{CaCO}_{3}$ & 0 & 47,500 (precipitate) \\
$\mathrm{MgCO}_{3}$ & 0 & 7,300 (precipitate) \\
$\mathrm{TDS}$ & 129,000 & 145,502
\end{tabular}

\subsection{Reactant Air}

Reactant air is compressed building air which has been purified to remove hydrocarbons and water. Air will be purified by flowing through a Whatman Zero Air Generator (see Section 6.0). Nominal flow rates through each test vessel will be $200 \mathrm{ml} / \mathrm{min}$. Air will exit through a condenser to remove water; this greatly reduces the amount of water loss from the test vessels.

Reactant air serves two purposes: 1) it keeps the oxygen content of the vessels constant, and 2) the slightly pressurized test vessel will keep the potentially contaminated room air out of the test vessels.

\subsection{REAGENTS AND FORMULATION}

\subsection{Reagent Chemicals}

In order to obtain the solution composition given in Table 1, various combinations of chemicals can be used. A spreadsheet has been developed which calculates the composition of a solution based on the added chemicals. Copies of typical outputs of the spreadsheet are shown in Appendix A for 60 and $90^{\circ} \mathrm{C}$ solutions. Many of the chemicals listed in the spreadsheet are not used in these examples. The inclusion of numerous chemicals in the spreadsheet allows the user the freedom to choose the needed chemicals based on availability, cost, and personal preference.

The algorithm to arrive at reagent concentrations was a trial and error method. The quantities of reagents required were estimated, and the spreadsheet calculated the total ionic content of the theoretical solution. Iteration was continued until an acceptable match was achieved.

The solution silica will be obtained by the addition of sodium silicate. Calculations showed that dissolution of solid silica phases would take extended periods of time ( $>1000$ days) in order for sufficient amounts of silica to dissolve.

Using sodium silicate will result in the formation of hydroxyl ions equal to the number of moles of sodium atoms added. These hydroxyls must be balanced by the addition of an equal number of moles of added hydrogen ions.

A word of caution in using the spreadsheet: the calculations assume that the chemicals dissolve completely and may therefore overestimate the composition of some species. The user must therefore be aware of potential solubility problems. A listing of the solubilities of various chemical is shown in Appendix B. However solubilities in the acidic solutions should not be a concern.

A typical example of chemicals used to make-up of the aqueous solution are listed in Table 2 along with the quantities required per 1000 I of solution. 


\begin{tabular}{|c|c|c|c|c|c|}
\hline No.: & Revision: & Date: & Page: & & \\
\hline TIP-CM-08 & 0 & 09/30/96 & 5 & of & 7 \\
\hline
\end{tabular}

Table 2. An example of the reagents and quantites required per 1000 liters of simulated aqueous solution.

\begin{tabular}{lll}
\hline Reagent & $\begin{array}{l}\text { Quantity @ 60 } \\
\text { (gms / 1000 liters) }\end{array}$ & $\begin{array}{l}\text { Quantity @ 90 } \mathrm{C} \\
\text { (gms / 1000 liters) }\end{array}$ \\
\hline $\mathrm{NaCl}$ & $34,893.3$ & $34,893.3$ \\
$\mathrm{NaNO}_{3}$ & $27,286.5$ & $27,286.5$ \\
$\mathrm{Na} \mathrm{SO}_{4}$ & $50,818.2$ & $50,596.0$ \\
$\mathrm{Na} \mathrm{SiO}_{3} \cdot 5 \mathrm{HO}_{2}$ & 204 & 370.0 \\
$\mathrm{MgSO}_{4} \cdot 7 \mathrm{HOO}_{2}$ & $10,138.0$ & $10,138.0$ \\
$\left.\mathrm{Ca}_{2} \mathrm{NO}_{3}\right) \cdot 4 \mathrm{HO}_{2} \mathrm{O}$ & $5,892.0$ & $5,892.0$ \\
$\mathrm{HSO}$ & 286.75 & 440.2 \\
2 & $6,482.8$ & $6,482.8$
\end{tabular}

The personnel responsible for making up the test solution is required to list in the Scientific Notebook or electronic media the chemicals and the quantities used in making up the test solutions.

\subsection{Purified Water}

The make up of the test solutions requires large quantities of low ionic content water is required. The use of LLNL de-ionized water is acceptable. This water has an ionic content typically less than $1 \mathrm{ppm}$. This is less than $0.001 \%$ of the ionic content due to the added chemicals. The source of the water used in testing will be recorded in the scientific notebook.

\subsection{Reactant Gas}

The reactant air will be purified before entering the test vessels.

\subsection{EQUIPMENT}

A balance that can measure to 0.1 grams is acceptable for make-up of the test solutions. An acceptable balance is:

Mettler Balance Model \# AT200

Serial Number 1114463500

An air purifier for cleaning the building compressed air is required. The following unit or equivalent is acceptable:

Whatmann Type 76-818NA Zero Air Generator

Unit Serial Number 768180065B

Tower Module Serial Number 76811-10116B

This air purifier removes hydrocarbon to $0.1 \mathrm{ppm}$. 


\begin{tabular}{|l|l|l|l|l|}
\hline No.: & Revision: & Pate: & Page: & \\
TIP-CM-08 & 0 & $09 / 30 / 96$ & 6 & 7 \\
\hline
\end{tabular}

\section{0}

PROCEDURE

The following procedure will be followed in making-up of the Simulated Concentrated Water solutions for the test vessels:

1) Purified water is emplaced in the cleaned vessel; the liquid level is slightly less than the required depth for testing. (Need to account for rise in water level due to the specimens and racks, and the density decrease due to raising the water temperature to the test temperature.)

2) The amount of purified water added to the test vessels is estimated.

3) The amount of reagent chemicals is determined and entered in the scientific notebook.

4) The purified water is heated to a nominal temperature of $40^{\circ} \mathrm{C}$. This will accelerate reactions that occur in solution.

5) The water will be stirred. The stirrer mounted on the vessel is sufficient.

6) The chemicals except for the sodium silicate and the acids are added to the solution.

7) The sodium silicate is added to the water.

8) The acid is added to solution to obtain $\mathrm{pH} 2$.

9) The test vessel is brought to $60^{\circ} \mathrm{C}$ and a sample of the test solution is withdrawn for analysis

10) The specimen racks are inserted into the test vessels. In order to minimize loss of volatile components from the solutions, all specimen racks will be inserted when the test vessel solutions are at $60^{\circ} \mathrm{C}$. (All the chemical species are expected to remain in solution under these conditions.)

11) The temperature of the solutions are brought up to testing temperture.

Note: The liquid level in the test vessels will self-adjust to the required level. If the liquid level is low, the liquid level control system will add purified water. If the liquid level is high, water removal by the air purge will occur; this may be slow but it will occur. It is preferred to add water rather than to remove water, since the control system shuts down the heaters when the liquid level is above a certain height.

Any data that is pertinent to this TIP shall be entered into the Scientific Notebook or electronic media for Activity E20-50. This shall include, but is not be limited to the chemical used lot \# manufacturer supplied analysis, and actual reagent chemical amounts used for make-up.

W. Glassley, private communication, 1996.

J.E. Harrar, J.F. Carley, W.F. Isherwood, and E. Raber, "Report of the Committee to review the Use of J-13 Well Water in Nevada Nuclear Waste Storage Investigations," Lawrence Livermore National Laboratory report UCID21867, Livermore California, January 1990. 
No.:

K.G. Knauss, W.J. Beiriger, D.W. Peifer, "Hydrothermal Interaction of Solic Wafers of Topopah Spring Tuff with J13 Water at 90 and $150^{\circ} \mathrm{C}$ Using Dickson-Type, Gold-Bag Rocking Autoclaves: Long-Term Experiments," Lawrence Livermore National Laboratory Report UCRL-53722, May 1987.

T.J. Wolery, Memo GCC-83-3/1773w, "Summary of Silica Solubilty Data for Acid-to-Neutral pH Conditions," 16 Nov. 1983. 